\title{
Prevalence of renal disorders among the residents of Canacona in India: analysis of the data from a free urological medical camp
}

\author{
R.B. Nerli, Tanmaya Metgud, M.B. Hiremath, Ajay Guntaka, Shivagouda Patil and Vikram Prabha \\ Dept. of Urology, KLE University's JN Medical College \& KLES Dr. Prabhakar Kore Hospital \& MRC, \\ Belgaum 590 010, India \\ rajendranerli@yahoo.in
}

\begin{abstract}
The high incidence of renal disorders/diseases in Canacona tuluk of Goa in India has been a matter of great concern. We analyzed the pattern of genitourinary problems in patients attending a free medical camp organised by the Department of Urology, KLES Kidney Foundation at Canacona. 298 patients attended the camp, which included 166 males and 132 females. $40.9 \%$ had urolithiasis, $12.9 \%$ had chronic renal failure and $12.8 \%$ had LUTS secondary to Benign Prostatic Hyperplasia. There is a high prevalence of renal disorders among the inhabitants of Canacona taluk. These disorders include urolithiasis and chronic renal failure.
\end{abstract}

Keywords: Health monitoring, Urolithiasis; renal disorders, mycotoxins, India

\section{Introduction}

The high incidence of renal disorders/diseases in Canacona taluk of Goa has been a matter of great concern for the local people for several decades. This problem has vexed the local medical practioners as well as health administrators. The local people have made several representations to the Director of health services, Goa. This matter has also been raised in the discussions of Rajya Sabha. Answering to queries raised by the member of parliament, Mr. Shantaram Naik in the Rajya Sabha, then, Union Minister of State for Health and Family Welfare Panabaka Lakshmi (Anon, 2007) admitted that according to ICMR (Indian Council for Medical Research), there was a high prevalence of renal diseases in the Canacona taluk and had been a matter of concern. The team from ICMR, NIOH (National Institute of Occupational Health, Meghaninagar, Ahmedabad) had visited and carried out environmental cum biological monitoring in February 2005 and had stated that clinically the disease seemed to be similar to Balkan Endemic Nephropathy (BEN), which was an environmentally acquired disease, possibly caused by mycotoxin produced by fungi in mouldy cereals and food products and aromatic compounds in drinking water $(\mathrm{NIOH}, 2005)$.

\section{Materials and methods}

A free medical examination camp was organised by the Dept of Urology, KLES kidney foundation at Dr. Dhavalikar Hospital, Canacona on $20^{\text {th }}$ Dec 2009. Precamp advertisements were displayed at various public locations in the Canacona town. The camp was targeted towards patients with genitourinary complaints. Patients attending the free camp were questioned regarding their symptoms. They were examined in detail, underwent screening ultrasonography, basic laboratory tests and Uroflowmetry if needed. A preliminary diagnosis was made and patients advised regarding treatment and further management. Patients were offered free samples of drugs wherever possible.

\section{Results}

A total of 298 patients attended the camp, of which $132(44.3 \%)$ were females and $166(55.7 \%)$ were males. The age distribution of the patients was as shown in Table 1, with $90(30.2 \%)$ patients being above the age of 50 years. The mean per capita income of the patients was above 36,000 per annum. Most of the patients belonged to middle income group. Through all the age groups the most common presenting symptom was pain in the loins/lumbar area. All these patients had history suggestive of urolithiasis. Of these, $20(6.7 \%)$ patients had been treated for urolithiasis in the past, and the treatment included endoscopy, ESWL (Extracorporeal shock wave lithotripsy) and open surgery. 54 (18.1\%) of the patients were using herbal/ayurvedic/allopathic treatment for the treatment/prevention of urinary stones. Urinary examination revealed abnormalities in $72(24.2 \%)$ patients which included pyuria, microscopic hematuria, crystaluria and bacteriuria. Ultrasonography revealed evidence of urolithiasis in $122(40.9 \%)$ patients. Of these $20(6.7 \%)$ showed evidence of hydronephrosis and hydroureter suggesting ureteric urolithiasis. 102 (34.2\%) patients showed evidence of renal calculi on ultrasonography. Most of these calculi were multiple, small $(<5 \mathrm{~mm})$ in size and distributed bilaterally. In 16 $(5.4 \%)$ patients the calculi were big in size $(>10 \mathrm{~mm})$ needing some form of therapy. The second most common group of complaints included lower urinary tract symptoms (LUTS) .These included both irritative as well as obstructive symptoms with the former being more
Research communication

CIndian Society for Education and Environment (iSee)
"Epidemiological study of renal disorder in India" http://www.indjst.org
Nerli et al. Indian J.Sci.Technol. 
common. $24(8.1 \%)$ females had irritative symptoms, with urine examination showing pyuria, bacteriuria and microscopic hematuria. Ultrasonography revealed cystitis like picture of the bladder. All these women were advised Urine culture sensitivity and put on urinary antiseptics. 38 $(12.8 \%)$ men, most of them above the age of 50 years had enlargement of prostate on their ultrasonography pictures. 26 of them were put on drugs which were a combination of $\alpha$-blockers (Tamsulosin) and $5 \alpha$-reductase (Dutasteride) inhibitors The remaining who had very poor flow (Qmax < $10 \mathrm{ml} / \mathrm{sec}$ ) were advised to undergo cystometry and further treatment. 4 (1.3\%) other women had history suggestive of overactive bladder. All were counselled and advised bladder relaxants, failing which they were advised to undergo cystometry and further treatment.

A total of $36(12.1 \%)$ patients had evidence of chronic renal failure (CRF). Of these 4 were already on hemodialysis, eight needed creation of a vascular access for hemodialysis. The rest were having evidence of CRF in the form of raised renal parameters, echogenic and small kidneys on ultrasonography. Most of these patients were in their $4^{\text {th }}$ to $5^{\text {th }}$ decade of life. All were advised medications, counseled about their renal status and need for dialysis/renal transplantation.

One adult male was diagnosed to have renal mass and two others had bladder mass on ultrasonography. 26 $(8.7 \%)$ of the patients had normal ultrasonography and urine examination.

\section{Discussion}

The lifetime prevalence of kidney stone disease is estimated at $1 \%$ to $15 \%$, with the probability of having a stone varying according to age, gender, race, and geographic location. In the United States, the prevalence of stone disease has been estimated at $10 \%$ to $15 \%$ (Norlin et al., 1976; Sierakowski et al, 1978; Johnson et al., 1979). Stone disease typically affects adult men more commonly than adult women. By a variety of indicators, including inpatient admissions, outpatient office visits, and emergency department visits, men are affected two to three times more frequently than women (Hiatt, et al., 1982; Soucie, et al., 1994; Pearle et al., 2005). However, there is some evidence that the difference in incidence between men and women is narrowing. The geographic distribution of stone disease tends to roughly follow environmental risk factors; a higher prevalence of stone disease is found in hot, arid or dry climates such as the mountains, desert, or tropical areas. However, genetic factors and dietary influences may outweigh the effects of geography. Seasonal variation in stone disease is likely related to temperature by way of fluid losses through perspiration and perhaps by sunlight-induced increases in vitamin D (Prince \& Scardino, 1960) noted the highest incidence of stone disease in the summer months, July through September, with the peak occurring within 1 to 2 months of maximal mean temperatures (Prince et al.,
1956). Heat exposure and dehydration constitute occupational risk factors for stone disease as well. The association of body size and incidence of stone disease has been investigated. In two large prospective cohort studies of men and women, the prevalence and incident risk of stone disease were directly correlated with weight and body mass index in both sexes, although the magnitude of the association was greater in women than men (Curhan et al., 1998; Taylor et al., 2005). The beneficial effect of a high fluid intake on stone prevention has long been recognized. In two large observational studies, fluid intake was found to be inversely related to the risk of incident kidney stone formation (Curhan et al., 1993; Curhan et al., 1997). Geographic differences in the incidence of stone disease have been ascribed in some cases to differences in the mineral and electrolyte content of water in different areas. Although several investigators reported a lower incidence of stone disease in geographic regions with a 'hard water supply compared with a 'soft' water supply, where water 'hardness' is determined by content of calcium carbonate (Churchill et al., 1978; Sierakowski et al., 1979) others found no difference. Schwartz and co-workers (Schwartz et al., 2002) found no association between water hardness and incidence of stone episodes, although they did observe a correlation between water hardness and urinary magnesium, calcium, and citrate levels.

With $40.9 \%$ of the patients attending the camp having evidence of urolithiasis on ultrasonography, it only confirms the fear that there is a high prevalence of urolithiasis among the residents of Canacona taluk. Of these $20(6.7 \%)$ had ureteric calculi and $16(5.4 \%)$ had renal calculi $>10 \mathrm{~mm}$ in size, needing intervention. With most of the factors such as diet, ancestry, climate, geography and quality of water being similar in the southern districts of Maharashtra (Sindhudurg), North Goa and North Karnataka (Karwar), this high prevalence of urolithiasis in the residents of Canacona is noteworthy. Certain local factors must be prevailing to explain the high incidence of urolithiasis.

The incidence of chronic renal failure in patients attending the camp was $12.1 \%$. This high prevalence of renal failure in the residents of Canacona is well established ( $\mathrm{NIOH}, 2005)$. Studies done in the past, as to the reason for this high prevalence, is that clinically this disease seems to be similar to Balkan Endemic Nephropathy (BEN). BEN is an environmentally acquired disease and the most plausible environmental agents responsible are the mycotoxins produced by fungi. These mycotoxins are natural products produced by the fungi that evoke a toxic response when consumed in low concentration by higher vertebrates. Ochratoxin A (OTA) is mainly produced by the species Aspergillus ochraceus and Penicillium verrucosum, which is mutagenic, oncogenic and nephrotoxic ( $\mathrm{NIOH}, 2005)$. OTA is responsible for chronic nephropathy in pigs and also may be the cause of BEN and some interstitial nephropathies 
seen in North Africa and France (NIOH, 2005). Ochratoxin $A$ has been associated with BEN and urothelial tumors (UT). Although a direct link between $B E N / U T$ and OTA remains to be established, epidemiological data correlates a moderate increase in serum OTA levels with a significantly higher incidence of nephropathy and urothelial tumors in humans. Studies carried out in several countries including Tunisia, Egypt and France have indicated a link between dietary intake of OTA and the development of renal and urothelial tumors (NIOH, 2005). A study done by Gilbert et al. (2001) shows the correlation between urinary OTA conc. and dietary intake appears stronger than the corresponding relationship between plasma OTA level and intake. Humans consume OTA by ingesting contaminated cereals, coffee, beer, wine, foods of animal origin etc. European Union has set the maximum permissible limit for OTA in raw cereal grains and cereal products at 5 and $3 \mu \mathrm{g} / \mathrm{Kg}$, respectively and in dried fruits at $10 \mu \mathrm{g} / \mathrm{Kg}(\mathrm{EC}, 2002)$.

It is for the benefit of the residents of Canacona that either Governmental or non-governmental organisations come forward to identify these avoidable toxins so that the prevalence of these disorders comes down.

\section{Conclusions}

There is a high prevalence of renal disorders including urolithiasis and chronic renal failure among the residents of Canacona.

\section{References}

1. Anon (2007) Concern over kidney disease in Canacona taluk of Goa. The Hindu. http;//www.thehindu.com/2007/08/18/stories/2007081 853120300.htm.

2. Churchill D, Bryant D, Fodor $\mathrm{G}$ and Gault $\mathrm{MH}$ (1978) Drinking water hardness and urolithiasis. Ann. Intern. Med. 88, 513-514.

3. Commission Regulation (EC) (2002) No 472/2002. Official J. Eur. Commun. 1-10.

4. Curhan GC, Willett WC, Rimm EB and Stampfer MJ (1993) A prospective study of dietary calcium and other nutrients and the risk of symptomatic kidney stones. N. Engl. J. Med. 328, 833-838.

5. Curhan GC, Willett WC, Rimm EB, Speizer FE and Stampfer MJ (1998) Body size and risk of kidney stones. J. Am. Soc. Nephrol. 9, 1645-1652.

6. Curhan GC, Willett WC, Speizer FE, Donna Spiegelman and Meir J Stampfer (1997) Comparison of dietary calcium with supplemental calcium and other nutrients as factors affecting the risk for kidney stones in women. Ann. Intern. Med. 126, 497-504.

7. Gilbert J, Brereton $P$ and Mac Donald S (2001) Assessment of dietary exposure to ochratoxin A in UK using a duplicate diet approach and analysis of urine and plasma samples. Food Addit. Contam.18, 10881093.
Vol. 3 No. 3 (Mar 2010)

ISSN: 0974- 6846
8. Hiatt RA, Dales LG, Friedman GD and Hunkeler EM (1982) Frequency of urolithiasis in a prepaid medical care program. Am. J. Epidemiol. 115, 255-265.

9. Johnson CM, Wilson DM, O'Fallon WM, Reza S Malek and Leonard T Kurland (1979) Renal stone epidemiology: A 25-year study in Rochester, Minnesota. Kidney Int. 16, 624-631.

10.National Institute of Occupational Health (NIOH) (2005) Annual report (executive summary). $\mathrm{p}: 49-52$.

11. Norlin A, Lindell $B$, Granberg $P O$ and Lindvall $N$ (1976) Urolithiasis: A study of its frequency. Scand. J. Urol. Nephrol. 10, 150-153.

12.Pearle MS, Calhoun EA and Curhan GC (2005) Urologic diseases in America project: urolithiasis. J. Urol. 173. 848-857.

13.Prince CL and Scardino PL (1960)A statistical analysis of ureteral calculi. J. Urol. 83, 561- 565.

14.Prince CL, Scardino PL and Wolan CT (1956) The effect of temperature, humidity and dehydration on the formation of renal calculi. J. Urol. 75, 209-215.

15.Schwartz BF, Schenkman NS, Bruce JE, Leslie SW and Stoller ML (2002) Calcium nephrolithiasis: Effect of water hardness on urinary lectrolytes. Urology. 60, 23-27.

16.Sierakowski R, Finlayson $B$ and Landes $R$ (1979) Stone incidence as related to water hardness in different geographical regions of the United States. Urol. Res. 7, 157-160.

17.Sierakowski R, Finlayson B, Landes R, Finlayson CD and Sierakowski N (1978) The frequency of urolithiasis in hospital discharge diagnoses in the United States. Invest. Urol. 15, 438-441.

18. Soucie JM, Thun MJ, Coates RJ, McClellan W and Austin H (1994) Demographic and geographic variability of kidney stones in the United States. Kidney Int. 46, 893-899.

19.Taylor EN, Stampfer MJ and Curhan GC (2005) Obesity, weight gain, and the risk of kidney stones. JAMA. 293, 455-462.
"Epidemiological study of renal disorder in India" http://www.indjst.org
Nerli et al. Indian J.Sci.Technol. 